\title{
Colabore!: uma plataforma para identificação e colaboração de especialistas
}

\author{
Hugo Tavares de Almeida ${ }^{1}$, Jean Carlos Paiva Miranda ${ }^{1}$, Vânia de Oliveira Neves ${ }^{2}$ \\ ${ }^{1}$ Departamento de Ciência da Computação, Universidade Federal de Juiz de Fora - \\ DCC/UFJF \\ ${ }^{2}$ Instituto de Computação, Universidade Federal Fluminense - IC/UFF \\ \{hugotavares,jean.paiva\}@ice.ufjf.br, vania@ic.uff.br
}

\begin{abstract}
We propose Colabore! platform whose objective is to offer means for identification and collaboration between specialists to find out the solution of a problem. After reporting a new problem and the fields of knowledge needed, the platform will suggest a group of professionals qualified to solve it.
\end{abstract}

Resumo. Este artigo propõe o desenvolvimento da plataforma Colabore! cujo objetivo é oferecer meios para identificação e colaboração entre especialistas para a resolver um problema. Após um novo problema e as áreas de conhecimento necessárias serem relatados, a plataforma irá sugerir um grupo de profissionais habilitados para resolvê-lo.

\section{Contextualização}

Em janeiro de 2019, ocorreu uma das maiores tragédias humanas mundiais, registrada em um dano ambiental minerário na cidade de Brumadinho/MG, ocasionando mais de 300 vítimas entre mortos e desaparecidos. Entre os desaparecidos, grande parte está soterrada em 10 milhões de $m^{3}$ de um fluido viscoso hiper-concentrado, em uma extensão de $5 \mathrm{~km}$ [Integração 2019]. Dado a natureza rara do problema, não há nenhuma tecnologia capaz de auxiliar as buscas e, então, uma equipe de cientistas de norte a sul do Brasil se reuniu para estudar e encontrar soluções para tal. A junção desses cientistas foi uma tarefa muito difícil e manual e, dado que eles se encontram em diversas regiões do país, o gerenciamento das discussões e a detecção da necessidade de envolver outros pesquisadores e/ou profissionais de outras áreas torna-se uma tarefa lenta e complexa [Piovezan 2019].

Dessa forma, identifica-se a necessidade de uma plataforma que seja capaz de automatizar a identificação de especialistas, sejam pesquisadores ou profissionais da indústria, para a resolução de um determinado problema. Essa plataforma também deve ser capaz de gerenciar a comunicação e artefatos gerados que possam surgir a partir de uma colaboração, considerando que profissionais das mais diversas áreas poderão participar. Esses colaboradores, por sua vez, podem não ser familiarizados e ter dificuldades com as ferramentas de gestão bastante utilizadas na área de tecnologia. Vale ressaltar que, apesar da motivação inicial ser relativa à solução do problema relacionado a uma tragédia, o sistema também pode ser utilizado para lidar com projetos das mais diversas naturezas. A plataforma Colabore!, descrita na próxima Seção, propõe-se a cumprir esses objetivos.

\section{Plataforma Colabore!}

A Colabore! permitirá que qualquer usuário previamente cadastrado seja capaz de requerer a solução de um determinado problema, informando sua descrição e as áreas que poderão contribuir para sua solução. A ferramenta consultará currículos de pesquisadores 
na plataforma Lattes bem como de profissionais da indústria no LinkedIn para então sugerir um grupo de profissionais habilitados a resolver esse problema. Em um primeiro momento, serão exibidas apenas as informações públicas desses profissionais. Caso eles já estejam cadastrados na plataforma, será dada ao usuário a opção de enviar um e-mail automático solicitando ajuda desse profissional para a resolução desse problema.

Uma vez definido o grupo de especialistas que irão contribuir para a resolução de um problema, a Colabore! oferecerá recursos para tal colaboração, tais como: fóruns de discussão, agendamento de reuniões, recursos para realização de reuniões a distância, compartilhamento e versionamento de arquivos, entre outros. Para isso, contará com a integração de sistemas open sources como GitHub ${ }^{1}$ e Trello ${ }^{2}$. Esforços já têm sido direcionados para o desenvolvimento desse projeto. No momento, desenvolvedores e gerentes de processo voluntários estão cooperando para construir a máquina de busca de colaboradores bem como a interface com o usuário.

\section{Contribuições do Sistema}

A Colabore! possibilitará uma identificação mais eficiente de profissionais aptos a resolver um determinado problema bem como nos mecanismos de gerenciamento dessa colaboração. Ela será uma plataforma aberta possibilitando que tanto empresas busquem profissionais da academia para auxiliá-los em um problema aplicado; quanto pesquisadores busquem empresas interessadas em aplicar suas teorias e abordagens, portanto possibilitando sua utilização para os mais diferentes fins. Isso torna difícil prever todos os benefícios e impactos sociais que ela pode trazer. Apenas para o caso de Brumadinho, por exemplo, a junção de vários profissionais que são capazes de construir uma tecnologia capaz de prever a localização das vítimas desaparecidas trará um impacto humanitário para as famílias dessas vítimas. Caso a plataforma seja utilizada para a resolução de um problema de despoluição do Rio Paraopeba, além dos impactos sociais que beneficiem a população que dependem desse rio, trará também impactos ambientais.

\section{Conclusões e Perspectivas Futuras}

Este artigo apresentou a proposta para desenvolvimento da plataforma Colabore! cujo principal objetivo é encontrar e unir pesquisadores e profissionais da indústria com conhecimentos complementares para que juntos possam trabalhar na solução de um problema.

A Colabore! ainda é um protótipo, mas espera-se que ela se torne uma plataforma pública disponível para toda a população. No futuro, pretende-se utilizar um sistema de recomendação de profissionais próprio para, a partir de profissionais que já colaboraram na solução de um problema, identificar quais áreas e profissionais poderiam ajudar na solução de outro problema similar.

\section{Referências}

Integração, T. (2019). Cientistas da ufjf desenvolvem tecnologia para auxiliar nas buscas em brumadinho. http://bit.ly/CienciaPorBrumadinhoTV. Acesso em: 10/05/2019

Piovezan, S. (2019). Como rede de cientistas usa dados para tentar achar corpos em brumadinho. http://bit.ly/CienciaPorBrumadinhoUOL. Acesso em: 10/05/2019.

\footnotetext{
1 https://github.com/

2 https://trello.com
} 